\title{
Extraosseous Ewing's Sarcoma: Pictorial Review of Imaging Findings, Differential Diagnosis, and Pathologic Correlation
}

\author{
Alan Alexander ${ }^{1} \quad$ Kyle Hunter $^{2} \quad$ Michael Rubin $^{3} \quad$ Ambarish P. Bhat ${ }^{4}$ \\ ${ }^{1}$ Department of Radiolog, Imaging Medical Associates, Inc., \\ Northridge, California, United States \\ 2Department of Radiology, Cleveland Clinic, Cleveland, Ohio, \\ United States

\begin{abstract}
Address for correspondence Ambarish P. Bhat, MD, Section of Vascular and Interventional Radiology, Department of Radiology, University of Missouri Columbia, One Hospital Drive, Columbia, Missouri 65212, USA (e-mail: bhatap@health.missouri.edu).
\end{abstract}

${ }^{3}$ Department of Radiology, Akron Children's Hospital, Akron, Ohio, United States

${ }^{4}$ Section of Vascular and Interventional Radiology, Department of Radiology, University of Missouri Columbia, Columbia, Missouri, United States
Abstract
Keywords
- Ewing's sarcoma
- musculoskeletal soft tissue
- oncology
- pediatric
- rhabdomyosarcoma

Extraosseous Ewing's sarcoma (EES), first described in 1969, is a malignant mesenchymal tumor just like its intraosseous counterpart. Although Ewing's sarcomas are common bone tumors in young children, EESs are rarer and more commonly found in older children/adults, often carrying a poorer prognosis. We discuss the multimodality imaging features of EES and the differential diagnosis of an aggressive appearing mass in proximity to skeletal structures, with pathologic correlates. This review highlights the need to recognize the variability of radiologic findings in EES such as the presence of hemorrhage, rich vascularity, and cystic or necrotic regions and its imaging similarity to other neoplasms that are closely related pathologically.

\section{Introduction}

Ewing's sarcoma was first described in 1921 by James Ewing as an osteolytic bone tumor composed of malignant small round cells. ${ }^{1,2}$ Extraosseous Ewing's sarcoma (EES) was first described in 19693; it is a malignant mesenchymal tumor much rarer than its intraosseous counterpart. The few case series and reports of EES that have been published in English literature in the last decade have been listed in - Table 1..$^{4-8}$ There are a few malignant and benign entities that may mimic an EES on imaging and therefore, it is essential that radiologists be familiar with this entity and its radiological aspects to help render an accurate diagnosis. This article depicts the imaging appearances and findings of five EESs in various anatomical sites, involving multiple modalities (-Table 2). Pathologic features of EESs are discussed. This review is written with the intent to enhance the existing knowledge base/awareness among radiologists of this rare entity.

\section{Discussion}

Ewing's sarcomas are common bone tumors in children. ${ }^{9} \mathrm{EES}$ is rarer, more commonly found in older children/adults, and often carries a poorer prognosis. ${ }^{5,10}$ EES has increasingly been reported from diverse sites whose origin has been attributed to ectopic neural and neuroectodermal proliferations. Genetic studies have suggested that EESs are in the same family as primitive neuroectodermal (PNET) tumors. Furthermore, genetic studies have demonstrated reciprocal published online

May 31, 2021
DOI https://doi.org/

$10.1055 / \mathrm{s}-0041-1729770$

ISSN 0971-3026 (c) 2021. Indian Radiological Association

This is an open access article published by Thieme under the terms of the Creative Commons Attribution-NonDerivative-NonCommercial-License, permitting copying and reproduction so long as the original work is given appropriate credit. Contents may not be used for commercial purposes, or adapted, remixed, transformed or built upon. (https://creativecommons.org/licenses/by-nc-nd/4.0/).

Thieme Medical and Scientific Publishers Private Ltd. A-12, Second Floor, Sector -2, NOIDA -201301, India 
Table 1 Published studies pertaining to Extraosseous Ewing's sarcoma in the past decade

\begin{tabular}{|l|l|l|l|}
\hline Author & Year & Type of study & No of cases \\
\hline${\text { El Weshi et } \mathrm{al}^{5}}^{5}$ & 2010 & Case series & 57 \\
\hline Muratori et al & & Case series & 29 \\
\hline Barnardt and Roux $^{6}$ & 2020 & Case series & 2 \\
\hline Mathew et al & 2013 & Case report & 1 \\
\hline Bang et al $^{7}$ & 2019 & Case report & 1 \\
\hline
\end{tabular}

Table 2 Patient demographics and location of tumors

\begin{tabular}{|l|l|l|l|}
\hline Age $(\mathrm{y})$ & Sex & Location & Imaging characteristics \\
\hline 1 & Male & Occipital scalp ( - Fig. 1) & $\begin{array}{l}\text { Heterogeneous subcutaneous soft tissue lesion without bony invasion on computed } \\
\text { tomography }\end{array}$ \\
\hline 7 & Female & Posterior neck (-Fig. 2) & $\begin{array}{l}\text { Subcutaneous soft tissue lesion, hypoechoic with hyperechoic foci and internal } \\
\text { vascularity on Doppler }\end{array}$ \\
\hline 26 & Female & Left thigh (-Fig. 3) & $\begin{array}{l}\text { Predominantly solid with heterogeneous echogenicity and cystic areas/internal } \\
\text { vascularity. Mildly T1 and T2 hyperintense solid mass with peripheral enhancement } \\
\text { and central necrosis }\end{array}$ \\
\hline 19 & Female & Right inguinal (-Fig. 4) & $\begin{array}{l}\text { Soft tissue mass with heterogeneous increased multicysitc T2 hyperintense mass } \\
\text { with septations. Heterogeneous enhancement with areas of cystic change/necrosis }\end{array}$ \\
\hline
\end{tabular}

translocation of $\mathrm{t}(11 ; 22)(\mathrm{q} 24 ; \mathrm{q} 12)$ in approximately $95 \%$ of patients, with the remainder demonstrating $\mathrm{t}(21 ; 22)$ (q22; q12) translocation. ${ }^{11,12}$ Generally, these tumors are commonly seen in the paravertebral regions or in the deep soft tissues of the extremities, with lower extremities having a higher propensity than upper extremities. ${ }^{9}$ Patients with EES often note a rapidly growing soft-tissue mass, with about one-third being painful secondary to compression of adjacent structures. They often present in the second decade of life. There is a mild male predominance and predilection for Caucasians. There has not been any evidence of familial or environmental influence. ${ }^{11-14}$

Radiographs may demonstrate a nonspecific soft-tissue mass in proximity to a bone without gross osseous involvement. ${ }^{9,15,16}$ Computed tomography (CT) usually shows a soft tissue mass with similar attenuation as skeletal muscle (-Fig. 1) $\cdot^{9,15}$ Adjacent bone involvement is uncommon (-Fig. 1)..$^{9,15}$ Calcification is exceedingly rare ${ }^{9,15}$ and this feature was a consistent imaging appearance in our patients.

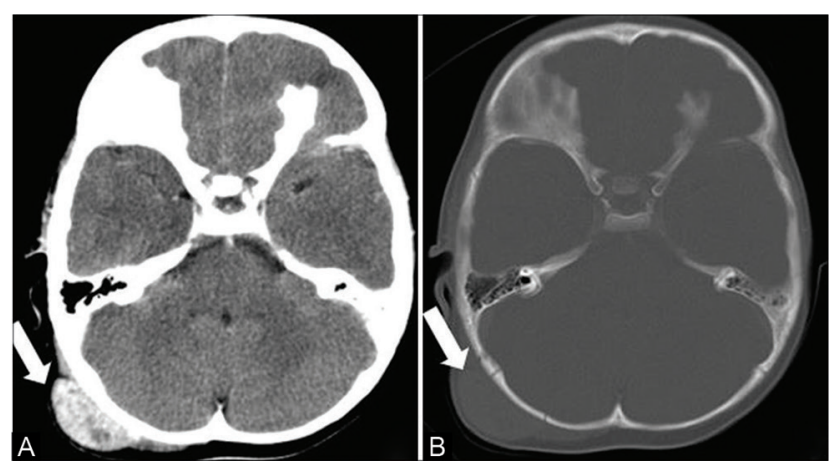

Fig. 1 (A, B) Axial CT (A) shows a circumscribed homogeneous subcutaneous mass in the right occipital scalp (white arrows). Bone windows (B) shows no erosion of the calvarium by the mass (white arrows). CT, computed tomography.

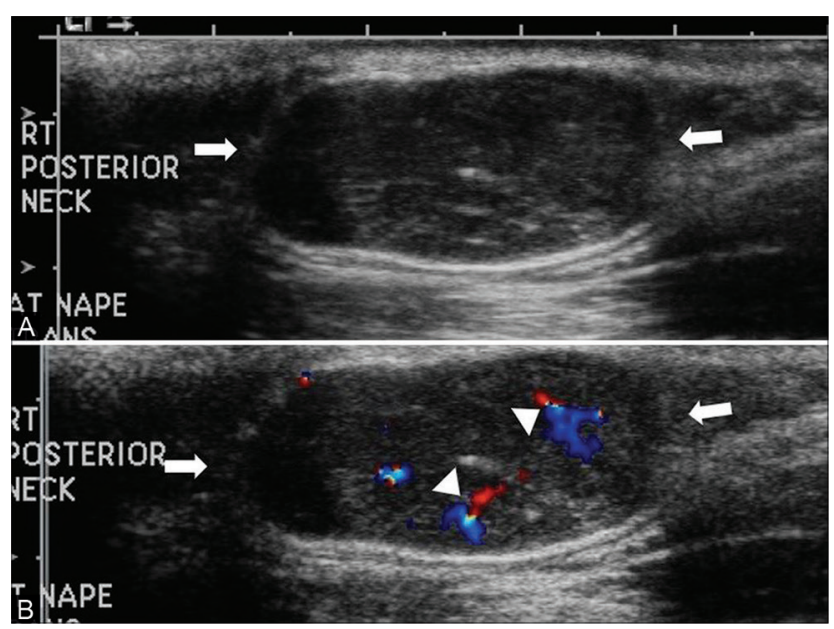

Fig. 2 (A, B) Sagittal ultrasound images (A, B) show a circumscribed solid hypoechoic mass (white arrows) with small echogenic striations and mild internal vascularity (arrowheads) in the subcutaneous soft tissue of the right posterior neck.

Sonographic findings are variable and nonspecific, and often demonstrate a hypoechoic, heterogeneous mass with internal vascularity ( - Fig. 2). ${ }^{9,15}$ Cystic change and necrosis may be seen (-Figs. 3 and $\mathbf{4}$ ). ${ }^{9,15}$

Findings on magnetic resonance imaging (MRI) include a mass with signal intensity similar to skeletal muscle on T1-weighted imaging (-Figs. 5 and $\mathbf{6})^{9,15}$; internal areas of hemorrhage may be seen as high T1 signal (-Fig. 3).9,15 On T2-weighted images, the mass often demonstrates a heterogeneous intermediate to hyperintense signal. High T2 signal areas representing foci of cystic or necrotic changes are common (-Fig. 4). ${ }^{9,15}$ On postcontrast images, there is often heterogeneous enhancement (-Figs 3-6). High-flow vascular channels or flow voids may also be seen (-Fig. 5) which is extremely common, although not unique to EES. ${ }^{9,15}$ Some of 
these masses may be quite complex, having undergone cystic degeneration/necrosis, and may contain internal septations ( Fig. 4). ${ }^{9,15}$ Fluid-fluid levels may also be observed. . $^{13,15,17,18}$
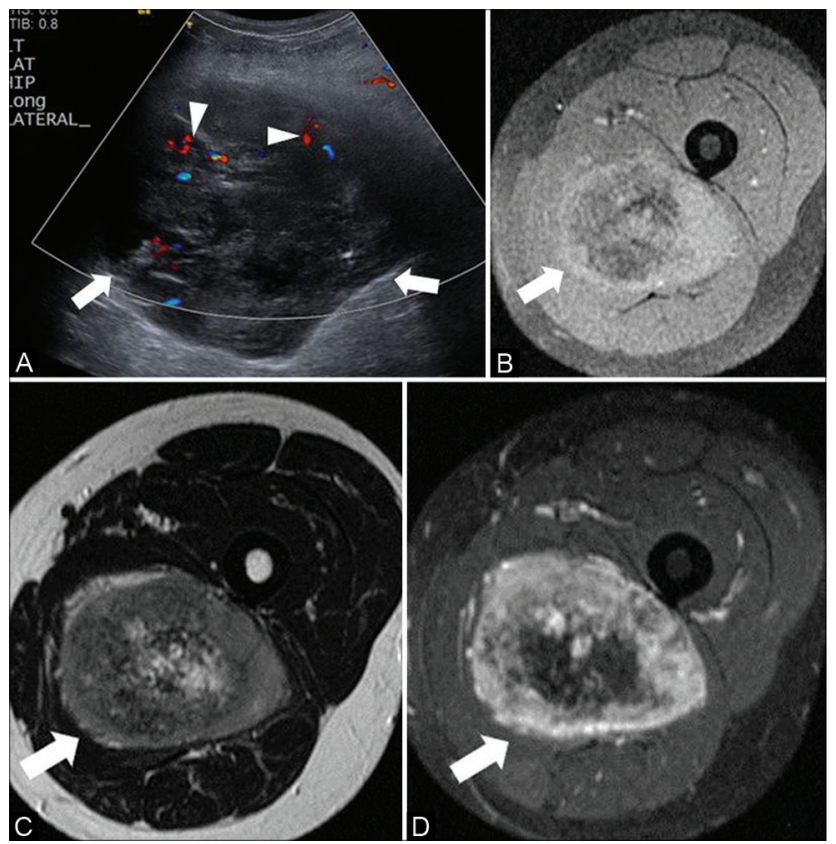

Fig. 3 (A-D) Sagittal ultrasound image (A) of the left proximal thigh shows a mass with heterogeneous echogenicity (white arrows) which is predominantly solid with some areas of cystic change/necrosis. Internal vascularity (white arrowheads) is seen with Doppler imaging. The axial T1 (B), T2 (C), and postcontrast (D) MRI images of the proximal thigh show a mass with mixed T1 and T2 signal and thick inhomogeneous peripheral enhancement with areas of central necrosis (white arrows). MRI, magnetic resonance imaging.
On gross pathological specimen, EES often appears gray-yellow or gray-tan with lobulations and a soft texture. ${ }^{9}$ Histopathology confirms EES via monotonous proliferation of small blue round cells solidly packed withintracellular glycogen which may indent nuclei ( - Figs. 7 and 8). ${ }^{9}$ Cystic/necrotic regions demonstrating rich vascularity, and areas of hemorrhage are often present. Membrane staining is almost always positive for CD99 (- Figs. 7 and 8) ${ }^{19,20}$ Histologic staining for FLI1, demonstrating $\mathrm{t}(11 ; 22)$, will provide definitive diagnosis ( - Fig. 8). ${ }^{19}$

Treatment often involves neoadjuvant chemotherapy typically with ifosfamide and etoposide followed by a combina-

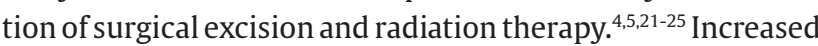
tumor burden and distant metastasis at presentation are associated with a poor overall survival. ${ }^{4}$ The 5 -year survival for patients with localized disease is around $60 \%$ and $40 \%$ for patients with metastatic disease. ${ }^{26}$

\section{Differential Diagnosis}

Differential considerations of EES mainly include rhabdomyosarcoma and synovial sarcoma ( - Table $\mathbf{3}$ ).

Neuroblastoma and lymphoma are less common considerations. Benign entities such as a venous malformation, especially the microcystic type, soft-tissue abscesses, and hematomas can also mimic a soft tissue tumor. Rare tumors, such as extraosseous mesenchymal chondrosarcomas, may also be included in the differential for an EES.

Rhabdomyosarcoma is the most common soft tissue malignancy in children and may be painless though rapidly growing. CT will demonstrate a soft-tissue density (-Fig. 9) with heterogeneous enhancement \pm adjacent bony

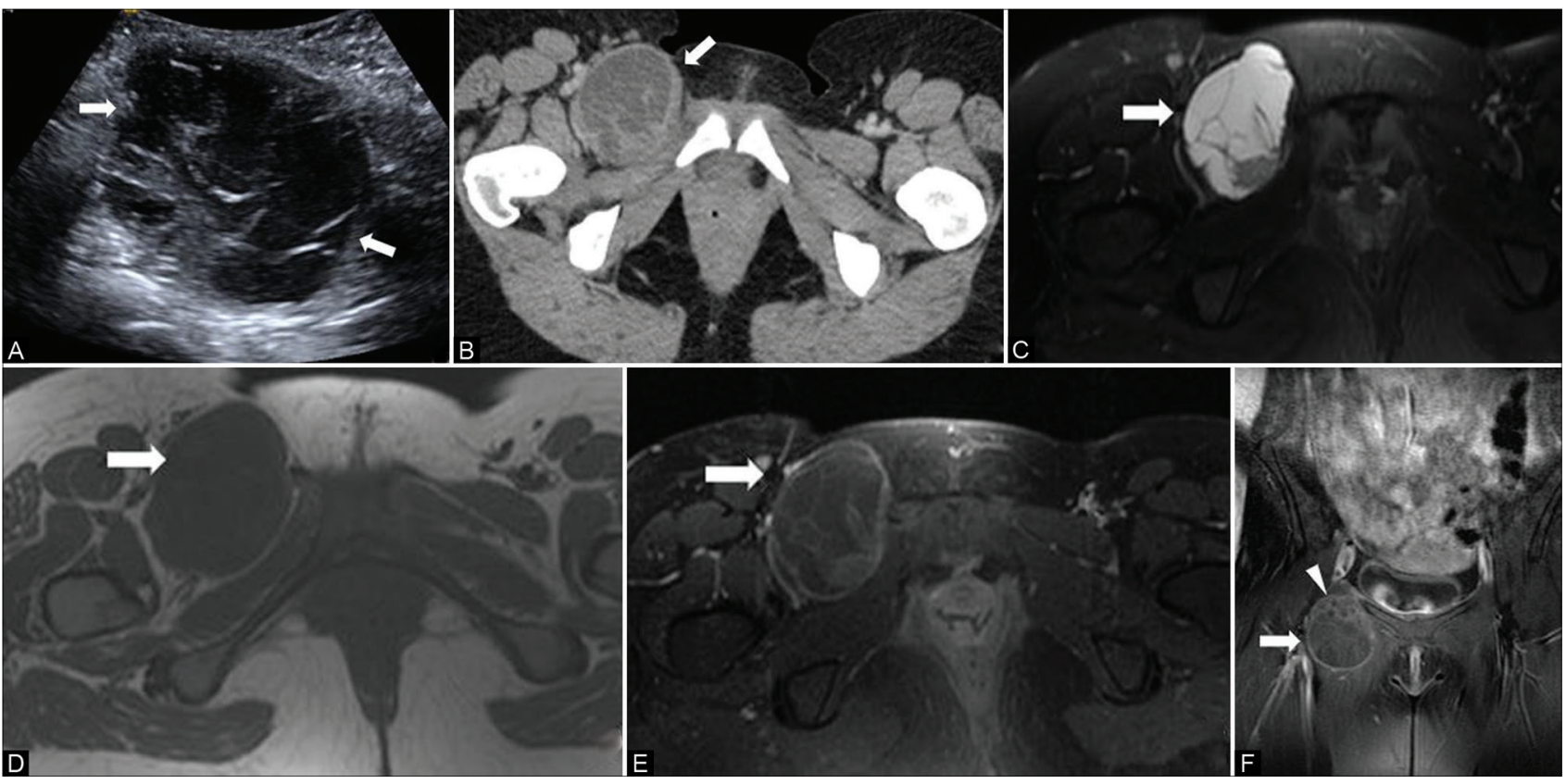

Fig. 4 (A-F) Sonographic image (A) demonstrates a predominantly hypoechoic mass (white arrows) in the right groin with internal septations. Axial CT (B) demonstrates a heterogeneous well-circumscribed soft-tissue mass (white arrows) in the right groin without evidence of calcification. Axial T2 fat sat (C), T1 (D), postcontrast axial T1 (E), and coronal (F) MRI images demonstrate a complex predominantly multicystic mass, in the right groin (white arrow) with a thin rim of peripheral enhancement and an eccentric inhomogeneous soft tissue component at its superior aspect (white arrowheads). CT, computed tomography; MRI, magnetic resonance imaging. 


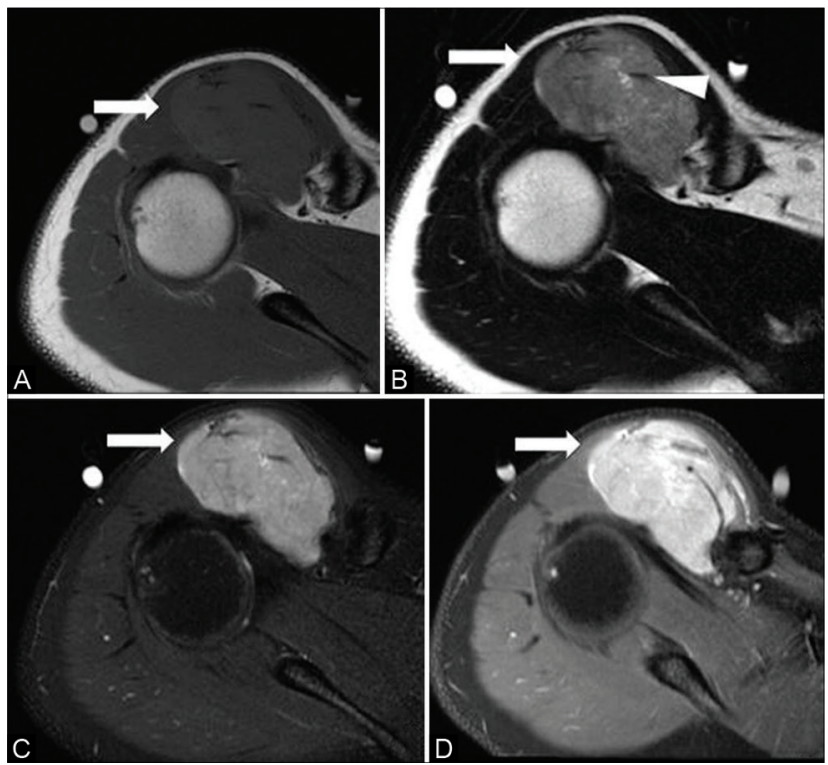

Fig. 5 (A-D) Axial T1 (A), T2 (B), T2 fat sat (C) postcontrast T1 fat sat (D), MRI images demonstrate a T1 isointense and T2 hyperintense enhancing mass (white arrows) within the right anterior deltoid muscle. Flow voids representing vessels (arrowhead in B). MRI, magnetic resonance imaging.
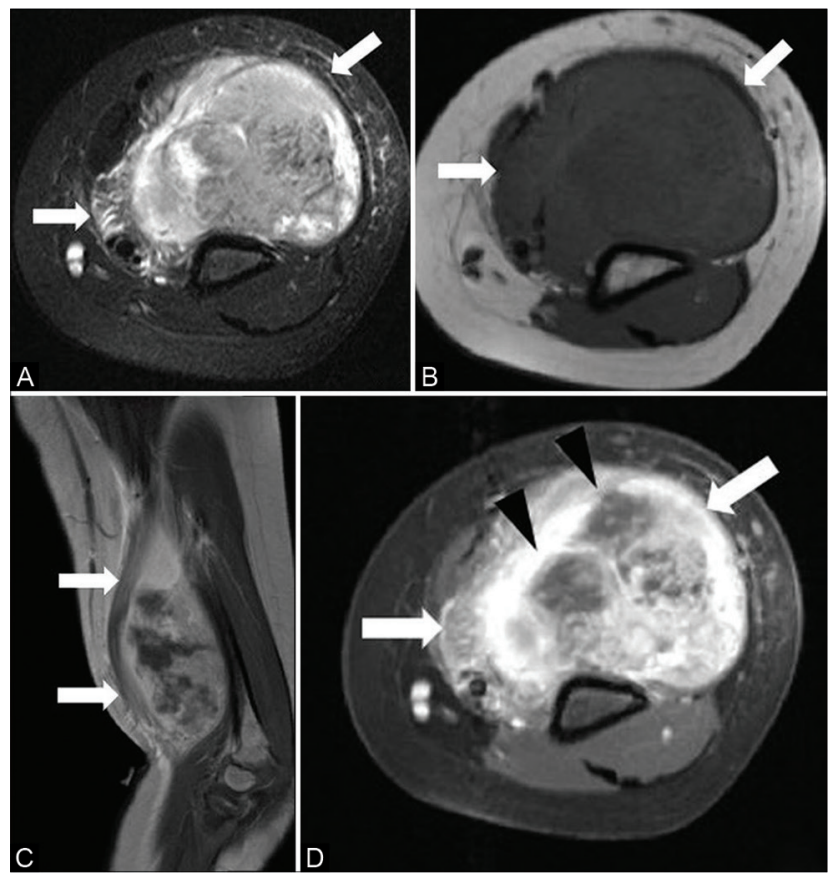

Fig. 6 (A-D) Axial STIR (A), axial T1 (B), sagittal and axial (C, D) postcontrast MRI images demonstrate a T2 hyperintense and T1 isointense mass with heterogeneous enhancement and areas of cystic change/necrosis (black arrowheads) within the left biceps muscle (white arrows). MRI, magnetic resonance imaging.

destruction. ${ }^{27}$ MRI demonstrates T1 isointensity to muscle \pm areas of hemorrhage and $\mathrm{T} 2$ hyperintensity to muscle associated with avid enhancement. ${ }^{28}$ There may be prominent flow voids (in alveolar subtype). Embryonal, alveolar, and pleomorphic histologic subtypes, all show skeletal muscle differentiation which is key to histopathological diagnosis $\left(-\right.$ Fig. 9)..$^{27-29}$

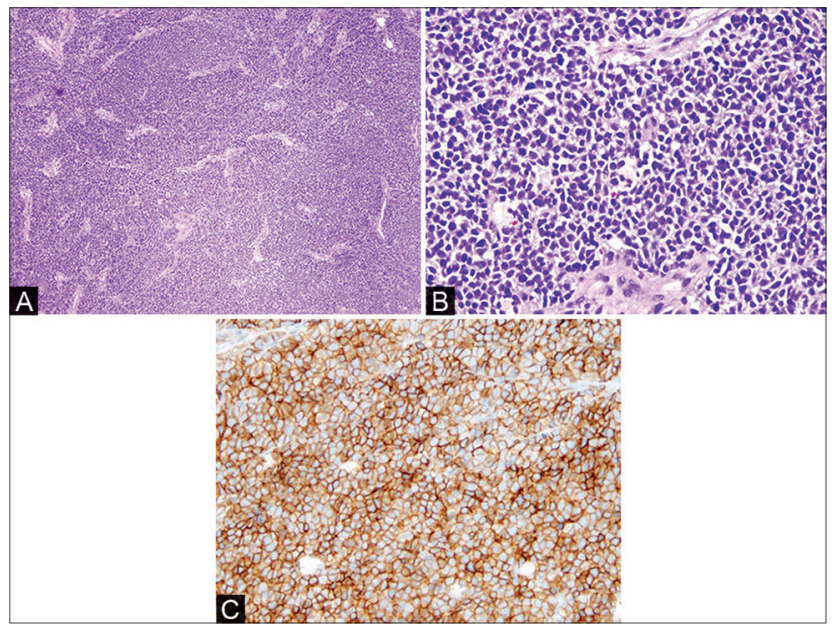

Fig. 7 (A-C) Histopathological images from patient in Fig. 5: Low (A) and high (B) power views of the classic round blue cell look that is seen with neuroblastoma, rhabdomyosarcoma, Ewing's sarcoma, and lymphoma. Immunohistochemical stain for CD-99 (C), which is a Beta 2 Microglobulin on the outside of the cell gives the brown outline. In a mass CD-99 is not specific for Ewing's sarcoma but is highly characteristic.

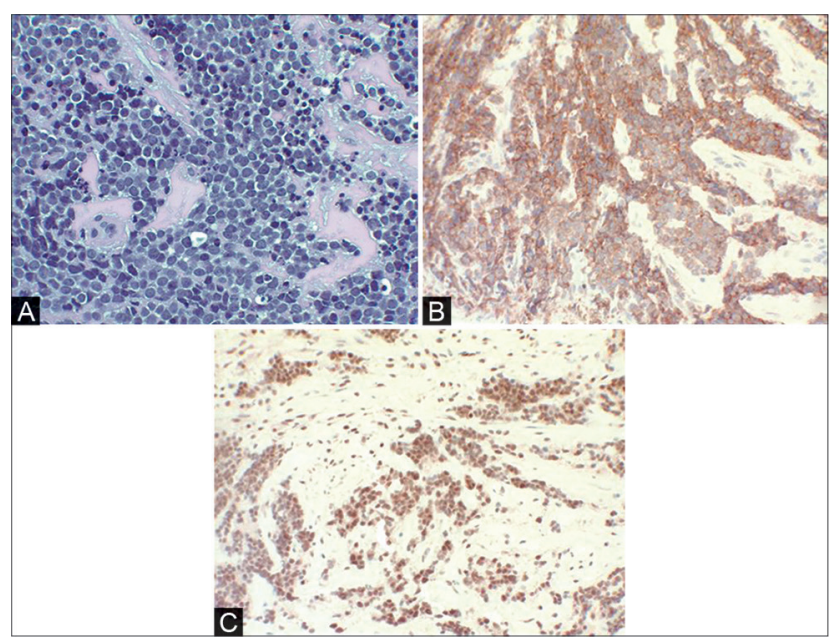

Fig. 8 (A-C) Histopathological images from patient in Fig. 6: High power view $(\mathbf{A})$ of the small round blue cell tumor. The CD99 staining (B) demonstrates a brown rim around the cells, highly characteristic of, though not specific for, Ewing sarcoma. The FLI1 (C) is a new immunohistochemical stain that looks for the chromosome 11-22 translocation (EMS-FLI1) which is characteristic of Ewing's sarcoma and stains the nucleus brown as seen in this patient.

Synovial sarcomas are the most common nonrhabdomyosarcomatous childhood malignancies of the lower extremities. $^{30}$ These slow growing masses have predilection for juxta-articular regions. ${ }^{30,31} \mathrm{CT}$ examination will demonstrate a heterogeneous soft-tissue mass with or without calcifications ( - Fig. 10). MRI demonstrates a mass, generally isointense to muscle on T1-weighted imaging, with heterogeneous and hyperintense T2 signal from necrosis, areas of hemorrhage, and bands of fibrosis. The combination of largely cystic areas and prominent hemorrhagic foci often creates a "bowl of grapes appearance." ${ }^{30}$ Although the poorly differentiated subtype is histologically similar to EES, monophasic 
Table 3 Differential diagnosis for Extraosseous Ewing's sarcoma

\begin{tabular}{|l|l|l|l|l|}
\hline Tumor & Age (peak) & Sex & Location & Imaging \\
\hline Rhabdomyosarcoma & First decade & $\begin{array}{l}\text { Slight male } \\
\text { predilection }\end{array}$ & $\begin{array}{l}\text { Anywhere in the body. The } \\
\text { alveolar and pleomorphic } \\
\text { variants having a predilec- } \\
\text { tion for extremities }\end{array}$ & $\begin{array}{l}\text { Heterogeneous magnetic resonance imaging } \\
\text { (MRI) signal intensity and enhancement. Flow } \\
\text { voids. Bone involvement in 25\% }\end{array}$ \\
\hline Synovial sarcoma & $\begin{array}{l}\text { Third decade } \\
\text { of life }\end{array}$ & $\begin{array}{l}\text { Female } \\
\text { predilection }\end{array}$ & Juxta-articular regions & $\begin{array}{l}\text { "Bowl of grapes" and "triple sign" appearance } \\
\text { on MRI from areas of necrosis and hemorrhage. } \\
\text { Calcification in 30\% of patients. }\end{array}$ \\
\hline $\begin{array}{l}\text { Neuroblastoma } \\
\text { One }\end{array}$ & No sex predilection & Adrenal and paravertebral & $\begin{array}{l}\text { Necrosis or hemorrhage, and calcifications are } \\
\text { common. MRI demonstrates high and low T1 } \\
\text { and T2 signal, related to calcification, hemor- } \\
\text { rhage, and necrosis. }\end{array}$ \\
\hline $\begin{array}{l}\text { Extraosseous } \\
\text { mesenchymal } \\
\text { chondrosarcoma }\end{array}$ & Second to third & $\begin{array}{l}\text { Female } \\
\text { predilection }\end{array}$ & Head and neck & $\begin{array}{l}\text { Central or eccentric mineralization. MRI } \\
\text { variable low signal mineralization with T2 } \\
\text { hyperintensity and intense heterogeneous } \\
\text { enhancement }\end{array}$ \\
\hline $\begin{array}{l}\text { Venous } \\
\text { malformation }\end{array}$ & Any age & No sex predilection & No site predilection & $\begin{array}{l}\text { Highly vascular lesion with thrombus, or phleb- } \\
\text { olith, on imaging }\end{array}$ \\
\hline
\end{tabular}

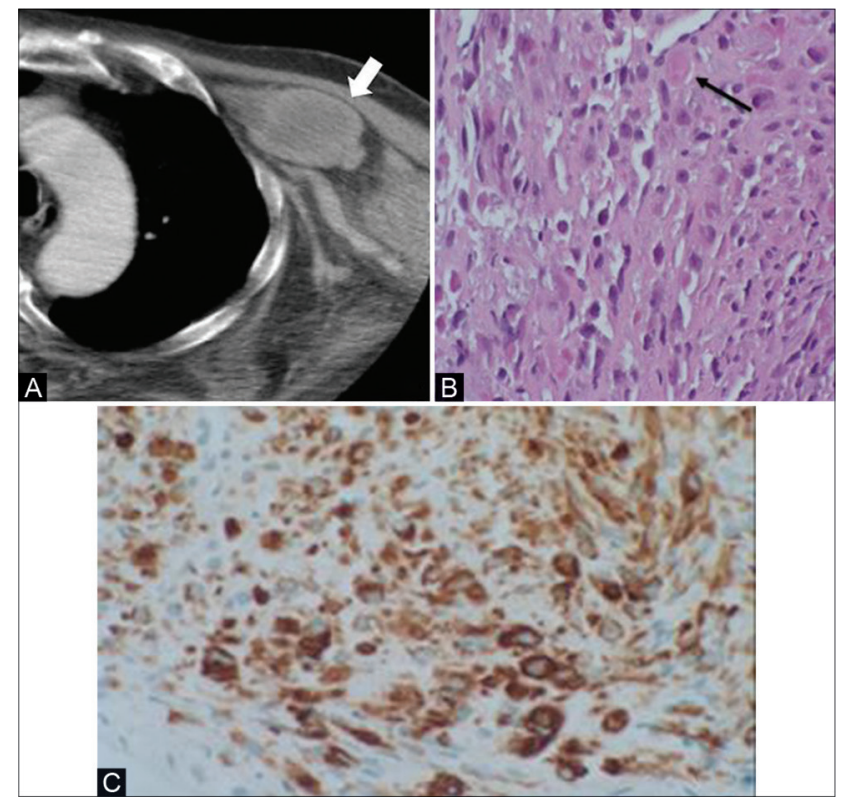

Fig. 9 (A-C) Axial CT image (A) demonstrates a left axillary mass (white arrow). Hematoxylin and eosin magnification $\times 400$ specimen (B) demonstrating skeletal muscle differentiation (black arrow). Rhabdomyoblasts highlighted by desmin stain (C). CT, computed tomography.

subtype reveals uniform atypical spindle cells, while biphasic subtypes have an epithelial element ( - Fig. 10).32 "Synovial" is a misnomer, as these tumors are not derived from synovium. Cytogenetic studies show translocation of $(\mathrm{x} ; 18)^{30,32-35}$

Outside of the adrenal gland, neuroblastomas (NBLs) are often paravertebral in location but in a younger demographic than EES. ${ }^{36,37}$ Laboratory assessment will commonly show elevated urinary catecholamine levels. ${ }^{36}$ Bony metastases are common and may be the presenting finding. ${ }^{36}$ On ultrasound, NBLs are heterogeneous solid lesions, mostly echogenic. ${ }^{36}$ The masses may appear heterogeneous from necrosis or hemorrhage, and calcifications are common. ${ }^{36} \mathrm{CT}$ or MRI can accurately assess the location and the size of the primary tumor

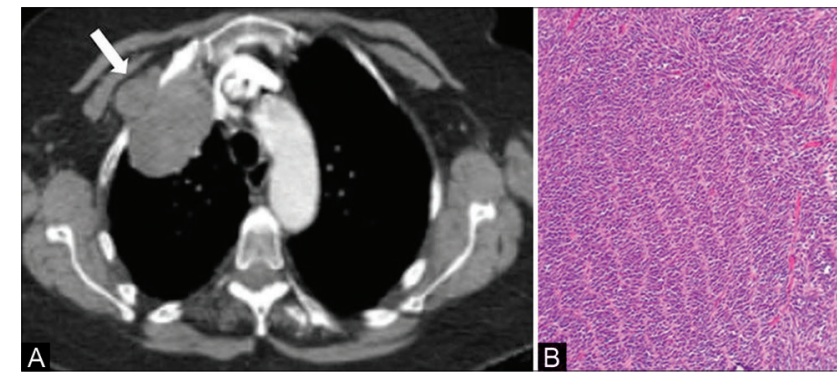

Fig. 10 (A, B) Axial CT (A) demonstrates a soft tissue mass (white arrow) in the anterior right upper thorax extending between the ribs. Hematoxylin and eosin magnification $\times 160$ (B) shows short, uniform, moderately atypical spindle cells, consistent with monophasic synovial sarcoma. CT, computed tomography.

and identify vascular encasement which determines tumor resectability. ${ }^{36,37}$ Coarse, finely stippled, or curvilinear calcifications are seen in $85 \%$ of the neuroblastomas. ${ }^{36}$ MRI demonstrates high and low signal on T1 and T2 imaging, related to calcification, hemorrhage, and necrosis. ${ }^{36,38}$ Microscopic features include immature, undifferentiated sympathetic cells. ${ }^{39-42}$

Lymphomas are differentiated from EES via identification of lymph node involvement; EES rarely involves lymph nodes. $^{43-45}$

Extraosseous mesenchymal chondrosarcomas are painless, slowly growing masses with chondroid matrix (-Fig. 11). The lesion is extremely rare in patients younger than 20 years of age. On CT, a soft tissue mass with similar attenuation to muscle is demonstrated with either central or eccentric mineralization. ${ }^{46,47}$ Necrosis may be present, and enhancement is heterogeneous. MRI findings include a soft-tissue mass containing variable low-signal mineralization with isointensity to muscle on T1-weighted imaging and hyperintensity on T2-weighted imaging and intense heterogeneous enhancement ( - Fig. 11). ${ }^{46}$ Histopathologic features include a biomorphic appearance with well-differentiated cartilage surrounded by sheets of closely packed undifferentiated cells. Stains are positive for S100, neuron-specific 


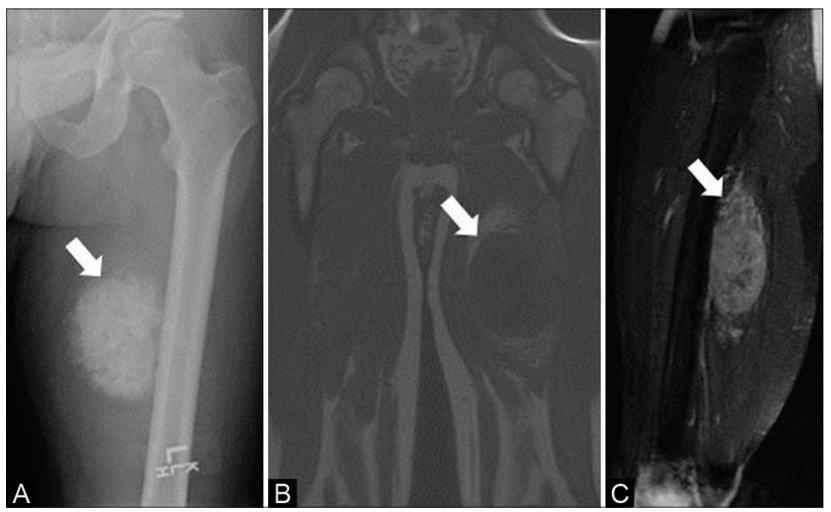

Fig. 11 (A-C) Extra osseous mesenchymal chondrosarcoma of the left thigh. AP radiograph of the femur (A) showing a calcified mass (white arrow) in thigh. The mass (white arrow) is T1 isointense (B) with enhancement (white arrow) on the postcontrast images (C). AP, anteroposterior.

enolase, and Leu-7, and negative for actin, epithelial membrane antigen, and cytokeratin. ${ }^{47-51}$

Benign entities including venous malformations, soft-tissue abscesses, and hematoma can be distinguished based on several key features. Rapidly growing venous malformations can be distinguished by identifying a highly vascular lesion with thrombus or phlebolith on imaging. Soft-tissue abscesses are often thick rimmed, with irregular peripheral enhancement, and the patient usually has systemic and local symptoms of infection. Hematomas may show dark signal on susceptibility weighted sequences due to presence of blood products. ${ }^{52-56}$

\section{Conclusion}

EES should be considered in the differential diagnosis when a circumscribed, aggressive appearing mass is encountered in the lower extremities or paravertebral regions of an older child/adolescent. Features, like flow voids, T1 signal similar to muscle, proximity to bone without gross osseous involvement in the early stages, cystic changes/necrosis, and lack of calcification, are seen in EES and are helpful in narrowing the differential diagnosis.

\section{Declaration of Patient Consent}

The authors certify that they have obtained all appropriate patient consent forms. In the form, the patient(s) has/have given his/her/their consent for his/her/their images and other clinical information to be reported in the journal. The patients understand that their names and initials will not be published and due efforts will be made to conceal their identity, but anonymity cannot be guaranteed.

\section{Funding}

None.

\section{Conflicts of Interest}

None declared.

\section{References}

1 Ewing J. Classics in oncology. Diffuse endothelioma of bone. James Ewing. proceedings of the New York Pathological Society, 1921. CA Cancer J Clin 1972;22(2):95-98

2 Cripe TP. Ewing sarcoma: an eponym window to history. Sarcoma 2011;2011:457532

3 Tefft M, Vawter GF, Mitus A. Paravertebral "round cell” tumors in children. Radiology 1969;92(7):1501-1509

4 Muratori F, Mondanelli N, Pelagatti L, et al. Clinical features, prognostic factors and outcome in a series of 29 extra-skeletal Ewing Sarcoma. Adequate margins and surgery-radiotherapy association improve overall survival. J Orthop 2020;21:236-239

5 El Weshi A, Allam A, Ajarim D, et al. Extraskeletal Ewing's sarcoma family of tumours in adults: analysis of 57 patients from a single institution. Clin Oncol (R Coll Radiol) 2010;22(5):374-381

6 Barnardt P, Roux F. The role of imaging in the evaluation of extraskeletal Ewing's sarcoma. SA J Radiol 2013;17:30-33

7 Bang JS, Adsul N, Lim JH, Jang IT. Extra-osseous Ewing sarcoma of sciatic nerve masquerading as benign nerve sheath tumor and presented as lumbar radiculopathy: Case report and review of literature. World Neurosurg 2018;115:89-93

8 Mathew D, Prince DN, Mahomed N. Extra-skeletal Ewing Sarcoma of the chest wall in a child. SAJ Radiol 2019;23(1):1733

9 Murphey MD, Senchak LT, Mambalam PK, Logie CI, Klassen-Fischer MK, Kransdorf MJ. From the radiologic pathology archives: ewing sarcoma family of tumors: radiologic-pathologic correlation. Radiographics 2013;33(3):803-831

10 Kim SW, Shin H. Primary intradural extraosseous Ewing's sarcoma. J Korean Neurosurg Soc 2009;45(3):179-181

11 Downing JR, Head DR, Parham DM, et al. Detection of the $(11 ; 22)$ (q24;q12) translocation of Ewing's sarcoma and peripheral neuroectodermal tumor by reverse transcription polymerase chain reaction. Am J Pathol 1993;143(5):1294-1300

12 Nagaraj P, Srinivas CH, Rao R, Manohar S. Extra skeletal soft tissue Ewing's sarcoma with variant translocation of chromosome $\mathrm{t}(4 ; 22)(\mathrm{q} 35 ; \mathrm{ql} 2)-\mathrm{A}$ case report. J Orthop Case Rep 2013;3(4):12-15

13 Christie DRH, Bilous AM, Carr PJA. Diagnostic difficulties in extraosseous Ewing's sarcoma: a proposal for diagnostic criteria. Australas Radiol 1997;41(1):22-28

14 Bhat AP, Schuchardt PA, Bhat R, Davis RM, Singh S. Metastatic appendiceal cancer treated with Yttrium 90 radioembolization and systemic chemotherapy: A case report. World J Radiol 2019;11(9):116-125

15 O'Keeffe F, Lorigan JG, Wallace S. Radiological features of extraskeletal Ewing sarcoma. BrJ Radiol 1990;63(750):456-460

16 Marjara J, Al Juboori A, Aggarwal A, Davis RM, Bhat AP. Metalophagia: Splenic artery pseudoaneurysm after foreign body ingestion and retrieval. Radiol Case Rep 2020;15(8):1149-1154

17 Rose JS, Hermann G, Mendelson DS, Ambinder EP. Extraskeletal Ewing sarcoma with computed tomography correlation. Skeletal Radiol 1983;9(4):234-237

18 Schuchardt PA, Yasin JT, Davis RM, Tewari SO, Bhat AP. The role of an IVC filter retrieval clinic-a single center retrospective analysis. Indian J Radiol Imaging 2019;29(4):391-396

19 Sandberg AA, Bridge JA. Updates on cytogenetics and molecular genetics of bone and soft tissue tumors: Ewing sarcoma and peripheral primitive neuroectodermal tumors. Cancer Genet Cytogenet 2000;123(1):1-26 
20 Fellinger EJ, Garin-Chesa P, Glasser DB, Huvos AG, Rettig WJ. Comparison of cell surface antigen HBA71 (p30/32MIC2), neuron-specific enolase, and vimentin in the immunohistochemical analysis of Ewing's sarcoma of bone. Am J Surg Pathol 1992;16(8):746-755

21 Galyfos G, Karantzikos GA, Kavouras N, Sianou A, Palogos K, Filis K. Extraosseous Ewing sarcoma: diagnosis, prognosis and optimal management. Indian J Surg 2016;78(1):49-53

22 El-Essawy MT. Extraskeletal Ewing's sarcoma. Saudi Med J 2009;30(6):840-843

23 Zagar TM, Triche TJ, Kinsella TJ. Extraosseous Ewing's sarcoma: 25 years later. J Clin Oncol 2008;26(26):4230-4232

24 Senne J, Davis R, Yasin J, Brimmo O, Evenski A, Bhat AP. Computed tomography guided radio-frequency ablation of osteoid osteomas in atypical locations. Indian J Radiol Imaging 2019;29(3):253-257

25 Marjara J, Hilli J, Davis RM, Bhat AP. Metastatic retro-crural lymph nodes from transitional cell carcinoma of bladder successfully treated with single session cryoablation. Radiol Case Rep 2020;15(8):1197-1201

26 Rodriguez-Galindo C, Spunt SL, Pappo AS. Treatment of Ewing sarcoma family of tumors: current status and outlook for the future. Med Pediatr Oncol 2003;40(5):276-287

27 McCarville MB, Spunt SL, Pappo AS. Rhabdomyosarcoma in pediatric patients: the good, the bad, and the unusual. AJR Am J Roentgenol 2001;176(6):1563-1569

28 Saboo SS, Krajewski KM, Zukotynski K, et al. Imaging features of primary and secondary adult rhabdomyosarcoma. AJR Am J Roentgenol 2012;199(6):W694-703

29 Newton WA Jr., Gehan EA, Webber BL, et al. Classification of rhabdomyosarcomas and related sarcomas. Pathologic aspects and proposal for a new classification-an Intergroup Rhabdomyosarcoma Study. Cancer 1995;76(6):1073-1085

30 Murphey MD, Gibson MS, Jennings BT, Crespo-Rodríguez AM, Fanburg-Smith J, Gajewski DA. From the archives of the AFIP: Imaging of synovial sarcoma with radiologic-pathologic correlation. Radiographics 2006;26(5):1543-1565

31 Jones BC, Sundaram M, Kransdorf MJ. Synovial sarcoma: MR imaging findings in 34 patients. AJR Am J Roentgenol 1993;161(4):827-830

32 Machen SK, Fisher C, Gautam RS, Tubbs RR, Goldblum JR. Utility of cytokeratin subsets for distinguishing poorly differentiated synovial sarcoma from peripheral primitive neuroectodermal tumour. Histopathology 1998;33(6):501-507

33 Sreenivasan N, Kalyanpur A, Bhat A, Sridhar PP, Singh J. CT diagnosis of cecal diverticulitis. Indian J Radiol Imaging 2006;16:451-452

34 Bhat P, Sridhar P, Sreenivasan N, Kalyanpur A. CT diagnosis of epiploic appendagitis-a case report. Indian J Radiol Imaging 2006;16:447-449

35 Patel PJ, Hieb RA, Bhat AP. Percutaneous revascularization of chronic total occlusions. Tech Vasc Interv Radiol 2010;13(1):23-36

36 Papaioannou G, McHugh K. Neuroblastoma in childhood: review and radiological findings. Cancer Imaging 2005;5:116-127

37 Kembhavi SA, Shah S, Rangarajan V, Qureshi S, Popat P, Kurkure P. Imaging in neuroblastoma: an update. Indian J Radiol Imaging 2015;25(2):129-136

38 Meyer JS, Harty MP, Khademian Z. Imaging of neuroblastoma and Wilms' tumor. Magn Reson Imaging Clin $\mathrm{N}$ Am 2002;10(2):275-302
39 Lonergan GJ, Schwab CM, Suarez ES, Carlson CL. Neuroblastoma, ganglioneuroblastoma, and ganglioneuroma: radiologic-pathologic correlation. Radiographics 2002;22(4):911-934

40 Sofka CM, Semelka RC, Kelekis NL, et al. Magnetic resonance imaging of neuroblastoma using current techniques. Magn Reson Imaging 1999;17(2):193-198

41 Ghouri MA, Gupta N, Bhat AP, et al. CT and MR imaging of the upper extremity vasculature: pearls, pitfalls, and challenges. Cardiovasc Diagn Ther 2019;9(suppl 1) :S152-S173

42 Schuchardt P, Yasin J, Davis RM, Thimmappa N, Bhat AP. Pelvic trauma: what the radiologist needs to know. Contemp Diagn Radiol 2019;42:1-6

43 Huh J, Kim KW, Park SJ, et al. Imaging features of primary tumors and metastatic patterns of the extraskeletal Ewing sarcoma family of tumors in adults: A 17-year experience at a single institution. Korean J Radiol 2015;16(4):783-790

44 Yasin J, Thimmappa N, Kaifi JT, et al. CT-guided cryoablation for post-thoracotomy pain syndrome: a retrospective analysis. Diagn Interv Radiol 2020;26(1):53-57

45 Bhat AP, Davis RM, Bryan WD. A rare case of bleeding duodenal varices from superior mesenteric vein obstruction -treated with transhepatic recanalization and stent placement. Indian J Radiol Imaging 2019;29(3):313-317

46 Murphey MD, Walker EA, Wilson AJ, Kransdorf MJ, Temple HT, Gannon FH. From the archives of the AFIP: imaging of primary chondrosarcoma: radiologic-pathologic correlation. Radiographics 2003;23(5):1245-1278

47 Hashimoto N, Ueda T, Joyama S, et al. Extraskeletal mesenchymal chondrosarcoma: an imaging review of ten new patients. Skeletal Radiol 2005;34(12):785-792

48 Chen Y, Wang X, Guo L, et al. Radiological features and pathology of extraskeletal mesenchymal chondrosarcoma. Clin Imaging 2012;36(4):365-370

49 Shakked RJ, Geller DS, Gorlick R, Dorfman HD. Mesenchymal chondrosarcoma: clinicopathologic study of 20 cases. Arch Pathol Lab Med 2012;136(1):61-75

50 Thimmappa N, Bhat AP, Bishop K, Nagpal P, Prince MR Saboo SS. Preoperative cross-sectional mapping for deep inferior epigastric and profunda artery perforator flaps. Cardiovasc Diagn Ther 2019;9(suppl 1) :S131-S142

51 Kabeel K, Marjara J, Bhat R, Gaballah AH, Abdelaziz A, Bhat AP. Spontaneous hemorrhage of an adrenal myelolipoma treated with transarterial embolization: A case report. Radiol Case Rep 2020;15(7):961-965

52 Turecki MB, Taljanovic MS, Stubbs AY, et al. Imaging of musculoskeletal soft tissue infections. Skeletal Radiol 2010;39(10):957-971

53 Legiehn GM, Heran MKS. Venous malformations: classification, development, diagnosis, and interventional radiologic management. Radiol Clin North Am 2008;46(3):545-597, vi

54 Koulouris G, Connell DA, Brukner P, Schneider-Kolsky M. Magnetic resonance imaging parameters for assessing risk of recurrent hamstring injuries in elite athletes. Am J Sports Med 2007;35(9):1500-1506

55 Petersen J, Thorborg K, Nielsen MB, et al. The diagnostic and prognostic value of ultrasonography in soccer players with acute hamstring injuries. Am J Sports Med 2014;42(2):399-404

56 Connell DA, Schneider-Kolsky ME, Hoving JL, et al. Longitudinal study comparing sonographic and MRI assessments of acute and healing hamstring injuries. AJR Am J Roentgenol 2004;183(4):975-984 